\title{
Games for Change: The Strategic Design of Interactive Persuasive Systems
}

\author{
Igor Revoredo Hosse ${ }^{(\varpi)}$ and Rachel Zuanon \\ Sense Design Lab, PhD and Master's Design Program, Anhembi Morumbi University, \\ São Paulo, Brazil \\ igrhosse@anhembimorumbi.edu.br, igor.hosse@gmail.com, \\ rzuanon@anhembi.br, rachel.z@zuannon.com.br
}

\begin{abstract}
Games for Change are designed to promote positive social impacts leading to reflection and behavior change of the players. However, it is a challenge to develop games that are motivators and, at the same time, stimulate positive changes. Therefore, in order to help designers to achieve these objectives, thirteen (13) design elements divided into three (3) structural strategic foci were proposed. To validate these elements, the Games for Change Ecocity (Brazil) and Half The Sky - The Game (USA) were analyzed. As a result, the design elements proposal helped to identify which aspects of each one of the analyzed games were responsible for the performance regarding the players behavior change and ability to motivate.
\end{abstract}

Keywords: Game Design · Games for Change · Motivation to Play · Flow

\section{Introduction}

Currently the planet spends more than 3 billion hours played per week [1]. If on one hand the consumption of digital games is increasing, on the other there are societal concerns on the impact of these experiences on players. According to Bogost [2], games are an expressive media able to generate radical changes in the behavior of the players and society. In this regard, researchers agree there is room to develop games aiming to contribute positively to the society [3-5].

Among the various types of increasingly popular digital games, Games for Change (GfC) belong to a special category of games intended to make players to consider, reflect and act in social and political issues, helping to promote positive change in the society.

GfC are included in a larger group identified as Serious Games, which include all games that have other explicit objectives in addition to entertainment. Despite having a small fraction of researchers, there are more developers who are interested in creating games that promote social impact. However, many games in this category are unable to motivate the players.

However, it seems to be difficult to achieve this objective because there is some resistance to Serious Games in general - which include GfC - given that many of them fail to provide motivation $[6,7]$. 
Thus, a set of strategic design elements is proposed here with the goal of helping designers to create GfC that promote positive behavior changes and are motivators. Altogether, there are thirteen (13) elements divided into three (3) different structural strategic foci: definition of a social or political objective; selection and abstraction of a physical system; and development of a motivating game. The thirteen (13) elements are: objective; theme; scenario and relevance; context; selection of a physical system; abstraction of a physical system; validity; clear objectives; choices; appropriate challenge; immediate feedback; social connection and polishing.

Accordingly, the next section examines GfC as persuasive systems; the concept of procedural rhetoric is presented and its use in digital games. In the third section, the challenge of motivating the players is discussed through two theories - Flow and SelfDetermination-Theory (SDT) - whose objective is to create intrinsic motivation in GfC. In the fourth section, three structural strategic foci and their design elements are proposed. In the last section, there is the comparative analysis between two games Ecocity and Half The Sky Movement - The Game - with the results to the proposed design elements.

\section{Games for Change as Persuasive Systems}

For GfC to achieve their main objective, which is to promote reflection and positive behavior changes in players in the physical world ${ }^{1}$, it is necessary that they have characteristics that persuade players to consider the social or political issue presented in the game.

In this regard, [2] states that digital games have the ability to create a special kind of rhetoric, the procedural rhetoric. According to him, games have a unique way of developing rhetoric through an abstraction of physical world systems, which are systems based on rules and interactions within the game, where players can experience the operation and thereafter interpret the system. Bogost [2] defines this unique type of game rhetoric as procedural rhetoric and classifies digital games as persuasive media. However, this rhetoric has specific characteristics compared to the traditional rhetoric: "I call this new form procedural rhetoric, the art of persuasion through rule-based representations and interactions rather than the spoken word, images, or moving pictures [2]".

In this sense, the procedural rhetoric is directly linked to the choices made by the digital game designers as to which elements of the physical world system they will use, which they will change and what they will create for the development of the game system. Depending on how the abstraction of the everyday world is developed, there is the possibility of persuading the players to reflect or positively change their behavior about a specific subject. Frank [8] argues that this abstraction should not mischaracterize the physical world because the players may have difficulty in applying their experiences in the game to the physical world. Consequently, there must be similarities between the game system and the physical world system.

${ }^{1}$ In this case, the term "physical world" is used to refer to the world outside the digital game. 


\section{The Motivation in Games for Change}

Motivations can be divided into intrinsic and extrinsic [9]. While the intrinsic motivation activities refer to activities that are done regardless of any external reward because the making itself is the reward; extrinsic motivation activities are conducted considering some external factor and are usually considered less motivating when compared to the intrinsic activities [9, 10]. In this regard, Jull [3] states that digital games are usually played without the need for any external benefit. Therefore, the activity of playing digital games can usually be considered intrinsic.

Nevertheless, it is challenging to develop digital games that can create intrinsic motivation in the players. Thus, two theories have been used to support the proposal of design elements related to the creation of intrinsic motivation in $\mathrm{GfC}$, they are: Theory of Flow and Self-Determination-Theory (SDT).

The Theory of Flow [10] is often employed [11, 12] as a tool for developing strategies aiming at increasing motivation in digital games. The Flow can be characterized as an experience of total absorption of the players in an activity in which there is the feeling of control and altered sense of time while they lose consciousness of "themselves". To achieve the Flow state, the activity has to have the chance of being completed, it has to have clear objectives and immediate feedback which allows total concentration [10]. As a result, GfC designers can provide the experience of total absorption of the players in the game by employing design elements aiming at ensuring the Flow.

Together, the SDT addresses three aspects not considered by the Theory of Flow: the need for autonomy; the importance of the relatedness; and the possibility of internalization of extrinsic motivation [9]. In this sense, this theory considers three basic needs for intrinsic motivation: competence, autonomy and relatedness.

Competence is an approach point between the Theory of Flow and SDT and highlights the need for challenge and the feeling of effectiveness as crucial elements for intrinsic motivation [13]. Consequently, the balance between the skills of the players and the challenges of the game is a priority in the development of current games [14]. On autonomy, Deci and Ryan [9] state this is one of the essential elements for intrinsic motivation and can be understood as the inverse of external control, in other words, a sense of freedom. Relatedness is another important point that may contribute to intrinsic motivation and to be understood as the experience of being connected with others [13]. These two aspects can contribute to the intrinsic motivation in GfC design in order to promote situations where the players have a greater chance of significant choices during the game, enhancing the player's experience variation, in addition to the connection tools with other players, allowing cooperation or competition among them.

\section{Proposal of 3 Structural Strategic Foci for the Design of Games for Change}

With the purpose of assisting GfC designers to overcome the challenge of creating a game that exploits a relevant issue for society and, at the same time, is motivating, three structural strategic foci are proposed: the definition of a social or political objective, 
selection and abstraction of a physical world system and the development of a motivating game. Each focus has a set of design elements specifying each point of attention in the game development.

The first focus - definition of a social or political objective - has four design elements: The objective (1) referring to the objective of the game as behavior change generator in the physical world; the theme (2) demonstrating the referred social or political issue; the scenario and relevance (3) that are connected to the environment developed for the game and their relevance regarding the game persuasion objective; and the context (4) discussing the relevance of the game to the social and political context of the physical world in which it is developed.

The second focus concerns the selection and abstraction of a physical world system. In this case the three design elements are: Selection of a physical world system (1) which identifies the physical system selected for the game and its alignment with the objective and theme of the game; the abstraction of a physical world system (2) which is related to the process of creating the game system and its similarity to the physical world system and validity (3) addressing the level of contribution of the game system with the theme and objective of the game.

The third focus - development of a motivating game - has six design elements directly related to the basic requirements for intrinsic motivation that are presented in the Theory of Flow and SDT, they are: clear objectives (1) referring to the clarity of the objectives in the game and its relation to the theme and objective of the game; choices (2) which relates to the level of freedom the game offers to the players; appropriate challenge (3) pointing to the difficulty presented by the game, which may result to the players motivation if balanced, or boredom and anxiety if it is unbalanced; immediate feedback (4) concerning the directions to the players on their position related to the objective of the game; social connection (5) dealing with the possibilities of the game in providing social connection tools for players and polishing (6) which addresses the use of visual or sound effects to further enhance the effectiveness of feedback.

\section{Implementation, Results and Discussion}

In order to validate the design elements of the three structural strategic foci presented, two GfC were analyzed. In order to ensure greater consistency in the analysis, there were chosen two games with characteristics as similar as possible to the platform and release date. Thus, the following games were selected: Ecocity ${ }^{2}$ (Sioux $\left.{ }^{3}, 2011\right)$ and Half The Sky - The Game ${ }^{4}\left(\right.$ Frima $^{5}$, 2013). Both are GfC on Facebook and they were released

\footnotetext{
${ }^{2}$ More information about the release of the Game for Change Ecocity available at: http:// www.meioemensagem.com.br/home/midia/noticias/2011/06/01/20110530Fox-lanca-socialgame-no-Dia-Mundial-do-Meio-Ambiente.html.

More information available at: http://www.sioux.com.br/.

${ }^{4}$ More information about the release of Half The Sky - The Game available at: http://www.gamesforchange.org/2013/02/half-the-sky-movement-the-game-launches-march-4/.

5 More information available at: http://www.frimastudio.com/.
} 
with a gap of less than two years (June 2011 and March 2013), respectively. Both games obtained different performances regarding players access number and impact on the physical world. Regarding the ability to motivate the players, the site AppData ${ }^{6}$ was used by the average position that is defined by the average number of accesses to the game compared to other games on Facebook in a given period of time. Accordingly, the most accessible game gets the first position. Thus, it can be noted that Half The Sky the Game (HtS) had a weaker performance compared to Ecocity (Table 1) because they had lower average position in 2013 , and still showed a greater tendency to drop on January $16^{\text {th }}, 2014$.

Table 1. Average position comparison between $\mathrm{HtS}$ and Ecocity with respect to Facebook accesses.

\begin{tabular}{l|l|l}
\hline Game & 2013 & $01 / 16 / 14$ \\
\hline Ecocity & 3921 & 4071 \\
\hline HtS & 4322 & 5256 \\
\hline
\end{tabular}

In order to measure the impact of the game HtS on the physical world, data provided by the game development team were used ${ }^{7}$. Consequently, by using tools within the game, such as direct links to provide cash aid or automatic donations by just playing the game, HtS got 250.00 donations of books, more than US\$ 163.000 in donations for fistula surgeries and more than US\$ 450.000 in direct donations to nonprofit organizations, representing a considerable impact on the physical world. However, Ecocity showed no tools in this regard, offering no directions to make the players act concretely in the physical world. As a side result, the game also showed no metric in that effect.

The results of each GfC, regarding the impact on the physical world and the players motivation, were used as a support for the analysis of games with respect to the proposed design elements. In addition to showing results similar to those presented by the website AppData and reports on the impact on the physical world, it was expected that the analysis also presented the main reasons why each game presented the respective results.

Therefore, the analysis of structural strategic foci was carried out as follows: for each design element, numerical values were assigned to classify how the game supports each one of them; zero indicates that it is not applicable because the game has not this feature to be evaluated; one means "partially meets"; and two represents "fully meets". In combination, the values of each element form an overall result for each structural focus. For easy reading, Table 2 shows the results for each focus.

\footnotetext{
${ }^{6}$ Website evaluating the popularity of online games through the number of accesses (www.appdata.com).

7 Learn more at: http://www.gamesforchange.org/g4cwp/wp-content/uploads/2011/06/HTS_ ImpactReport_October_web.pdf.
} 
Table 2. Performance of GfC assessed according to the proposed design elements

\begin{tabular}{l|l|l}
\hline Focus & $\mathrm{HtS}$ & Ecocity \\
\hline \multicolumn{2}{l|}{ (1) Definition of a social or political objective } \\
\hline Objective & 2 & 2 \\
\hline Theme & 2 & 2 \\
\hline Scenario and relevance & 2 & 1 \\
\hline Context & 2 & 2 \\
\hline Average & $\mathbf{2}$ & $\mathbf{1 . 7}$ \\
\hline
\end{tabular}

(2) Selection and abstraction of a physical world system

\begin{tabular}{l|l|l}
\hline Selection of a physical system & 2 & 1 \\
\hline Abstraction of a physical system & 2 & 1 \\
\hline Validity & 2 & 1 \\
\hline Average & $\mathbf{2}$ & $\mathbf{1}$ \\
\hline
\end{tabular}

(3) Development of a motivating game

\begin{tabular}{l|l|l}
\hline Clear objectives & 2 & 2 \\
\hline Choices & 1 & 2 \\
\hline Appropriate challenge & 1 & 2 \\
\hline Immediate feedback & 2 & 2 \\
\hline Social connection & 2 & 2 \\
\hline Polishing & 2 & 1 \\
\hline Average & $\mathbf{1 . 6}$ & $\mathbf{1 . 8}$ \\
\hline
\end{tabular}

\subsection{Half the Sky Movement}

$\mathrm{HtS}$ is part of a transmedia campaign (including a book, documentary, mobile games and game for Facebook) called Half the Sky Movement aiming to promote reflection and questioning of the women social oppression worldwide ${ }^{8}$. The player controls Radhika, an illiterate and poor woman who lives with her family in a modest house in India. Each game challenge is presented through a story related to several issues regarding women oppression, such as domestic violence and sexual exploitation. The first challenge the player faces, for an example, is when Radhika's daughter, Aditi, gets sick and the family does not have money to pay for her treatment. Thus, the player must

${ }^{8}$ More information available at: http://www.halftheskymovement.org/pages/movement. 
find a way to earn money, but first, the player must face Radhika's sexist husband, Bhanu, who does not like the idea of his wife finding a solution by herself to help their daughter.

There are three possible ways to continue the game. First, there is a map in which the player picks his next quest (the quests are unlocked according to the player's performance). Second, there is the predefined dialogues interface in which the player must click on the answers they find most convenient leading to different results. Third, there is a collection mini-game (e.g. used to collect mangos), in which the player must connect the same elements and use them to continue.

$\mathrm{HtS}$ provides three essential resources, the hope bonds, coins and energy. Hope bonds are the fastest way to play, through the purchase of coins, energy and even other powers. They are rare in the game, but it is possible to buy them with the physical world money. The coins represent the money in the game and are earned through completion of some activities, such as selling fruit in the market. Energy is required to perform any task in the game, so it is the feature that runs out faster. When the energy goes out, the only solutions are to wait until it automatically recharges; buy it using the hope bonds or ask friends on Facebook who also play the game to donate energy. The quickest option is to buy the hope bonds with physical money, which is reversed in donations to NGOs involved with the cause. There are three other ways to make donations in the game. First, access a list of partners who are NGOs involved the same cause of the game, enter the website and look for a way to help, which can be, for example, sign a petition. Second, donate physical money to the cause directly by the game. Third, that is automatically, because as the player goes on and reaches a certain level, some partner companies provide donations to NGOs, for example, money for surgeries in the Fistula Foundation. Moreover, as it is on Facebook, the game encourages the player to provide information on the cause through posts.

Therefore, with respect to the focus number one, the game meets all the criteria. There is a social objective, which is to talk about the exploitation of women in developing countries. There is also a clear intention to lead the players to act for the cause, either through donations, unlock automatic donations, access partner NGOs or share information with friends. The theme has social background and is adequate for the objective of the game. The scenario chosen, some developing countries - India, Kenya, Afghanistan and Vietnam - is relevant to the objective of the game, given the conditions of oppression to which women are subjected in these countries. Finally, the context in which the game was released contributes to the objective and theme, since women oppression is currently a major issue in society.

In $\mathrm{HtS}$, there is also compliance with focus number two. First, the chosen physical world system, which are the various social problems to be faced by women, complies with the theme and the objective of the game. Second, the system developed for the game does not mischaracterize the physical world system, as the quests deal with social problems often faced by women. Third, the system is valid because it contributes both to the theme of the game, which deals with the journey of Radhika against the problems that oppress women in developing countries, and for the social objective of the game, which is to talk about these social issues and also offer tools to conduct the largest number of players to actively participate in the cause. 
With respect to focus number three, $\mathrm{HtS}$ achieved a varied performance. Regarding the clear objectives, HtS presents all the necessary elements. The game helps the player to understand what needs to be done through explanatory windows explaining from the general objective of the game to the objective of each quest. When there is more than a quest going on, the game has visual cues with animations to be clicked so that the player continues. In addition, all the quest objectives are aligned with the social objective of the game and, although they seem to be challenging, they are likely to be completed.

Nevertheless, concerning choices, HtS limits the options of the player, for though offering choices, they are not significant. For example, in a part of the first quest, the player must convince her husband to find a way to get money to pay for the treatment of their sick daughter. In this sense, the game offers two options to the player during the dialogue. The player can choose if Radhika will confront her husband or will agree with him and stay silent. Whatever the choice, the player must perform the same actions to complete the quest, including harvest mangos and sell them at the town market to earn some money. There are not other ways to get the money, which makes the quest poorly varied. The only difference between the answers is that the score received from remaining silent ( 3 points) is less than that score obtained for facing the husband ( 7 points). However, the missing points can be easily recovered by selling mangos at the market again.

Regarding the appropriate difficulty level, there are three game situations that only partially meet the issue. First, there is energy shortage. The energy runs out really fast and prevents the player from taking any action. To ask energy for Facebook friends is only a stopgap solution because they can only give little amount of energy (5 points) in large time intervals $(1 \mathrm{~h})$. Thus, for every action in the game, it is usually necessary 4 friends to donate energy. As friends are not always available, the player needs to wait for the points automatically increase or use physical money, which can frustrate or bore the player. Second, the penalty for the getting the wrong answer during the dialogues is low and does not affect the development of the game. The player is not challenged, which can take them to boredom. Third, there is the collection interface where the player must collect the highest number of points in a limited time. It also provides poor variation, preventing the player to create strategies to get more points. The player can buy powers, which increase the time available for collection or offer double points, but for that, the player needs the hope bonds, which are very rare. As to the immediate feedback, HtS is appropriate because it provides a number of indications to the player on their position related to the objective of the quest and the game. The player can check their current position in the quests through indicative windows. For every action in the game, there are windows that show the value of earned resources, and a wide range of sound effects for every action, including move your mouse over quests, complete quests and select items. On social connection, HtS works properly. The sense of competition is generated through the bar showing their friends who have accounts on Facebook and also play the game. It also indicates the level of each player for comparison. There is also the possibility of cooperation. An example is the quest in which Radhika gathers a group to search for her friend's aggressive husband, who is a fugitive. In this situation, the player can recruit Facebook friends to help and complete it faster. Another way is to wait for the game itself to free artificial helpers, which can 
take hours. As it is within Facebook, there is the possibility of communication and chat messages between the participants of the game, besides creation of groups. Regarding polishing, HtS has visual and sound effects appropriate to strengthen the feedbacks of the game. When the player wins or spends resources such as energy, they are displayed in the center of the graphic interface and then they move along with the sound effects, until reaching their respective resource bar indicating to the player the type of earned resource.

\subsection{Ecocity}

Facebook Ecocity was released on June $5^{\text {th }}, 2011$, the World Environment Day. Fully developed in Brazil, the game received the certification of the National Geographic Society ${ }^{9}$ and aims to bring environmental discussions to the public, and also to have an impact in the physical world. The game does not have tools to direct the player to contribute directly to the cause, as donations. Therefore, there are no metrics available to verify the impact generated in the physical world.

The game is set in a fictional town that can be named by the player. The city faces problems like garbage in the streets, polluted river, abandoned buildings, air pollution and lack of energy. Through the resources offered by the game, the player must turn the city into an ecocity, that is, a sustainable city. In this regard, the player should pay attention to quality of life points. It begins negative, so the player's objective is to change it for positive points. With ecocredits, it is possible to buy other resources, such as energy, to go faster in the game. For each action or quest completed, experience points are awarded releasing new constructions for the player to use in the city. Energy is used to supply power to the buildings. Without it, the city does not produce money, products, waste or sewage. Products are needed to make the businesses work and can be produced in reforestation area or in the recycling stations. Money is needed to build and increase the city. Waste produced by homes and businesses needs to be stored in warehouses and then recycled. Sewage needs to be treated or it will be directed automatically by the game to the river, polluting it. There are quests, such as investing in public transportation, that help the player to win resources and increase experience points throughout the game. In friends, it is possible to visit their cities, help them to keep their cities in operation and also invite new friends. In the construction tab, it is possible to choose different types of interventions to increase the city and make it sustainable. There is the option of building homes concerned with the population growth; businesses that provide money to the city; infrastructure and decoration, which enhance the quality of life; structures for the power supply; structures for sustainability and expansion aiming to increase the size of the city.

Ecocity partially meets the requirements of focus number one. Regarding the definition of the objective, it is adequate because the objective of the game is to make the player aware and act positively concerning sustainability. The theme of the game,

${ }^{9}$ One of the largest scientific and educational non-profit institutions. Its interests include geography, archeology and natural science and environmental conservation promotion and also history. More information on: http://www.nationalgeographic.com/. 
consisting of the management of a city for sustainability, is also consistent because it is aligned with the social objective of the game. The social and political context is also appropriate as the game works with sustainability, matter of great relevance curretly. The scenario, on the other hand, lacks important elements that are found in the physical world, such as floods, possibility of creating awareness programs, hydropower plants, and alternative transportation, such as subways and bicycles. These missing elements create a gap between the game world and the physical world, reducing the possibility of generating positive behavior change in the player. The game also lacks tools to drive the player to be aware of and act in relation to sustainability, such as the possibility of donations, tips about the sustainability or indication of organizations involved with the cause.

With respect to focus number two, GfC Ecocity only partially meets the requirements. The physical world system, chosen as a basis for developing the game system, was the operation and administration of a city. The choice of this system is appropriate because it is aligned with the objective and theme of the game. However, the system allows actions that mischaracterize the physical world. For example, in a certain game situation, the city has poor quality of life, represented by the value of -246 points. The ideal strategy would be to clean up the river, which would improve the quality of life of city dwellers in 960 points. However, there are not enough coins to build the river treatment plant costing 10,000 coins. It is possible to buy newsstands for the city though. Each newsstand costs 410 coins and adds 30 points in quality of life. Thus, after creating 9 newsstands in the same block, the city began to offer a satisfactory quality of life. As a prize, the player receives bonus in business. In the physical world, however, the construction of a city block with several newsstands would hardly make positive influence in the city's quality of life. The game also does not meet fully the criteria of validity, because as it mischaracterizes the physical world, it is difficult to establish a more direct relationship between the game system and the physical world system.

With respect to focus number three, Ecocity meets most of the criteria presented. On the issue of clear objectives, the game meets all the necessary elements. All active quests have a fixed position in the player interface, making it easy to identify which quests must be completed. By clicking on each of the quests, a window shows all the steps to complete it, including the itens that have already been completed. The graphical interface is complete and easy to understand, according to the informational point of view, by displaying the level of all resources. In addition, the objectives seem to be challenging, because they require several steps to be completed and resources are not always available. Game objectives always deal with a sustainability problem, for example, creation of public transport or disposal of waste, aligned to the social objective of the game. Concerning the choices, the game offers several ways of achieving the quality of life. For example, while a player can invest more in decoration elements, another player can first try to win many coins with pollutant facilities, increasing it initially, and then replace the coal plant with a less polluting one, such as wind power plant, improving the quality of life in the city. Another player may prefer to follow the game's quests, which are gradually contributing to a city with better quality of life. In this sense, there is no dominant strategy, the decision is up to the player, increasing the possibility of intrinsic motivation. In Ecocity, another important feature to be considered is the appropriate 
challenge. At the beginning, the player has a significant amount of coins and energy to build the city and win the first quests. Over time, however, the player needs to understand the most efficient means of maintaining a sustainable city while solving the quests and earning experience points. This progression is varied, containing the easiest and most difficult quests. Energy is scarce and can be purchased with physical money too. However, if it runs out, the player can do other things as moving the city buildings, collect resources, etc. Besides the player only needs to wait a few minutes to increase energy, preventing them to get frustrated by not being able to interact. As to the immediate feedback, the game also meets all the criteria, because the game interfaces have all the necessary information to the player. Thus, there are direct information on what player needs to do when choosing a quest, to complete it and also to level up. Regarding polishing, the game partially works. Although the interface responds to player interaction with animations that emphasize interaction, the game has no sound feedback, which, in addition to making the visual feedback lose sound reinforcement, requires the player to stay all the time looking at the interface. The competition is generated through a dropdown bar, which indicates experience level of Facebook friends, who are players also. There are cooperation tools to advance in some quests in the game. For example, there is a quest in which the player needs to create a health center and store vaccines, which must necessarily be delivered by the neighbors. Another way is to visit the city from a neighbor and help collecting coins, causing the two to gain resources. The game also allows communication via posts, chat, and the creation of communities using the tools of Facebook. Moreover, through the game page on this social network, it is possible to use the forum in order to answer questions, find new friends interested in social issues or write comments about the game.

Comparing both analysis on the three suggested foci and the impact of each game in the physical world, two main points were identified. First, there was similarity between the results of the analysis based on three structural strategic foci and the game performance with respect to the popularity and impact on the physical world, validating the proposal of the design elements. Secondly, the result of the analysis showed the possible reasons for their performances in each structural focus. In this regard, while $\mathrm{HtS}$ satisfactorily met the proposed elements in foci one and two, which are more related to the impact on the physical world, it did not reached the same result in the focus related to the players motivation mainly because it did not meet the design elements - appropriate challenge and choices. This result is mainly because $\mathrm{HtC}$ does not offer strategic ways to overcome the greatest difficulties of the game, making the players to repeat the same action several times, which makes it frustrating at times. Moreover, the choices available in the game were not significant because they did not offer very different results.

Ecocity achieved median performance mainly on focus two because the game system mischaracterized the physical world system, which resulted in inadequate contribution to the theme and objective of the game, affecting the transfer of the players experience in the game to the physical world. Conversely, Ecocity showed better performance in the elements related to the ability to motivate with average performance only in polishing, mainly for lack of audible feedback and visual effects. 


\section{Conclusion}

Mainly through the study of procedural rhetoric and the Theory of Flow and SDT, thirteen (13) design elements divided into three distinct and strategic foci were proposed to assist GfC designers to develop games that cause positive social impact and that are motivators. Thus, Ecocity and $\mathrm{HtS}$ were analyzed to validate the proposed elements. As a result, the data related to the social impact and motivation of games through access data and social impact reports were similar to the results of the analysis by the proposed structural strategic foci, demonstrating the main reasons for each of the GfC performances. Consequently, through the results presented, it is possible to initially validate the proposed design elements, which are the main contribution of this research, with regard to the engagement and motivation, for the GfC development context, once it showed direct relationship between the application of design elements and the results of the user experience with these games. In future developments, there will be other tests with the above-mentioned design elements and also the development of games using them as a support.

\section{References}

1. Mcgonigal, J.: Reality Is Broken: Why Games Make us Better and How They Can Change The World. Penguim Press, New York (2011)

2. Bogost, I.: Persuasive Games: The Expressive Power of Videogames. MIT Press, EUA (2007)

3. Juul, J.: Half-Real: Video Games Between Real Rules And Fictional Worlds. MIT Press, EUA (2005)

4. Koster, R.: A Theory of Fun For Game Design. Paraglyph Press, Eua (2005)

5. Shaffer, D., Squire, K., Halverson, R., Gee, J.: Video Games And The Future of Learning. Phi Delta Kappan 87(02), 104-111 (2005)

6. Resnick, M.: Edutainment? No Thanks. I Prefer Playful Learning. In: The Associazione Civita report on Edutainment. (2004)

7. Mattar, J.: Games Em Educação: Como os Nativos Digitais Aprendem. Pearson Prentice Hall, São Paulo (2010)

8. Frank, A.: Balancing three different foci in the design of serious games: engagement, training objective and context. In: Proceedings of Digra (2007)

9. Deci, E.L., Ryan, R.M.: The What And Why of Goal Pursuits: Human Needs And The SelfDetermination of Behavior. Psychological Inquiry 11, 227-268 (2000)

10. Csikszentmihalyi, M.: Flow: The Psychology of Optimal Experience. Harper Perennial, EUA (2008)

11. Schell, J.: The Art Of Game Design: A Book of Lenses. Morgan Kaufmann, EUA (2008)

12. Fullerton, T.: Game Design Workshop: A Playcentric Approach To Creating Innovative Games. Morgan Kaufmann, EUA (2008)

13. Ryan, R., Rigby, C.S., Przybylski, A.: The Motivational Pull of Video Games: A SelfDetermination Theory Approach. Etr\&D 53(02), 67-83 (2006)

14. Przybylski, A., Rigby, C.S., Ryan, R.A.: Motivational model of video game engagement. Rev. Gen. Psychol. 14(02), 154-166 (2010) 